\title{
La definición lexicográfica de contorno fluctuante
}

\author{
JOSÉ-ÁLVARO PORTO DAPENA \\ Universidade da Coruña
}

En Porto Dapena (1997: 213) señalaba que una definición lexicográfica sobre todo cuando corresponde a un verbo - puede estar constituida por dos partes esenciales fácilmente diferenciables: el enunciado parafrástico, por un lado, y el contorno definicional, por otro. El primero representa lo que podría llamarse - aunque no sea del todo exacto- «definición propiamente dicha», en la medida en que incluye los rasgos semánticos intrínsecos del definido, es decir, los que lo caracterizan como miembro de un paradigma léxico-semántico, mientras que el segundo corresponde más bien a los rasgos meramente contextuales o de subcategorización, es decir, los encargados de establecer las características combinatorias — el aspecto puramente sintagmático- de ese mismo definido. La distinción de ambas partes es, además, muy sencilla, porque, de ellas, solo el enunciado parafrástico puede sustituir al definido o definiendum en cualquier enunciado. $\mathrm{Y}$ así, partiendo de una definición como

desvivirse. prnl. Mostrar incesante y vivo interés, solicitud o amor por alguien o algo,

observaremos que el enunciado parafrástico corresponde únicamente a la parte no subrayada, ya que en una expresión como

Julián se desvive por su familia,

puede sustituir a se desvive, resultando de ese modo

Julián muestra incesante y vivo interés, solicitud o amor por su familia.

Esto quiere decir, por otro lado, que por alguien o algo, esto es, la parte subrayada de la definición, representa el puro contorno, esto es, un complemento que desvivirse ha de llevar siempre que se realice en el discurso (en el ejemplo anterior corresponderá a por su familia).

Ahora bien, hasta aquí la cosa resulta muy clara y, como digo, bastante sencilla, pero se complica, en primer lugar, cuando observamos que el contorno no siempre aparece dentro del enunciado definicional, es decir, no solo puede ser integrado, como en el caso anterior, sino también no integrado (Porto Dapena, 2002: 313), como, por ejemplo, en

acusar. tr. Dep. Dicho de un atleta o de un jugador: Mostrar inferioridad o falta de preparación física, 
donde lo expresado - y subrayado por mí- antes de los dos puntos, es decir, delante del enunciado definicional, corresponde íntegramente, si bien de un modo indirecto, ${ }^{1}$ al contorno. Y, en segundo lugar, se complica todavía más cuando observamos que, en un mismo enunciado definicional, un determinado segmento puede funcionar en unos casos como contorno y en otros pertenecer al enunciado parafrástico, circunstancia que se da, por ejemplo, en esta otra definición:

comer. Tomar alimento,

en la cual alimento funciona como contorno tan solo cuando el verbo funciona como transitivo:

Ayer comimos una paella riquísima,

donde, lógicamente, paella riquísima constituye el alimento; pero a su vez pasa a formar parte de la paráfrasis, cuando el verbo se interpreta como intransitivo:

Ayer comimos con unos amigos $=$ Ayer tomamos alimento con unos amigos.

Pues bien, nos encontramos en este caso ante un elemento al que, precisamente por esa característica especial de poder funcionar alternativamente como contorno y como componente de la paráfrasis, propongo llamar contorno fluctuante, distinto del contorno opcional, cuyos respectivos alcances — sobre todo del primero - es precisamente lo que me propongo estudiar en las páginas que siguen.

\section{EN LAS DEFINICIONES DE ADJETIVOS}

Para empezar, estos dos tipos de contorno aparecen fundamentalmente en algunas definiciones de adjetivos y de verbos. En el caso de los adjetivos, pueden en teoría corresponder al sustantivo que acompañan o a posibles complementos de régimen, y en el de los verbos, al sujeto o a un complemento, siempre que la presencia de este no sea obligatoria en todos los contextos propios del definiendum.

\subsection{Con referencia al sustantivo afectado}

El carácter fluctuante se da, como digo, cuando el contorno reproduce el sustantivo - o hiperónimo del sustantivo - a que el adjetivo se refiere y este, además, es susceptible de utilizarse también como sustantivo. Un ejemplo, pues, de contorno fluctuante puede ser el que aparece en la siguiente definición tomada del Diccionario de uso del español (DUE) de M. Moliner:

adolescente adj. y n. Persona que está en la adolescencia,

\footnotetext{
1 Digo de un modo indirecto, porque no se indica propiamente el contexto semánticosintáctico, que es el que constituye el contorno, sino más bien el contexto referencial, esto es, la realidad extralingüística representada por el sujeto del verbo.
} 
cuyo definiens - o definición en sentido estricto - está constituido, como echa de verse, por un sintagma nominal cuyo núcleo sintáctico persona (subrayado por mí) es contorno en la interpretación adjetiva del definiendum, ya que lo que realmente repite el contenido de adolescente es tan solo la oración de relativo; de donde la equivalencia

Tengo un hijo adolescente $=$ Tengo un hijo que está en la adolescencia.

Pero notemos que, por otro lado, ese mismo elemento pasa a formar parte del enunciado parafrástico cuando el definiendum funciona como sustantivo:

Resulta dificil controlar a un adolescente $=$ Resulta dificil controlar a una persona que está en la adolescencia.

Como existe una tendencia generalizada a identificar el definiens con el puro enunciado parafrástico, no es frecuente - sobre todo en los diccionarios modernos- encontrarnos con definiciones de este tipo para los adjetivos, es decir, en las que aparezca integrado el sustantivo a que el adjetivo se refiere, aun en el caso de que dicho adjetivo, como en el ejemplo anterior, sea susceptible de emplearse como sustantivo. Nótese, efectivamente, que una definición así, constituida por un sintagma nominal, no cumpliría el principio de identidad categorial entre definiendum y definiens, $y$, por eso, la definición anterior se interpretaría más bien como representante del sustantivo y no del adjetivo adolescente. Quiero decir con esto que la tendencia actualmente es a evitar definiciones de adjetivos como la que acabamos de ver, y de ahí que el $D R A E$ limite la definición de adolescente a la pura paráfrasis:

adolescente. adj. Que está en la adolescencia. U. t. c. s.

lo que, por otro lado, no deja de representar un cierto inconveniente, habida cuenta de que esta última definición nunca correspondería a un sustantivo, circunstancia que exigiría una explicación que no se redujese, como es aquí el caso, a la simple indicación de que este adjetivo puede usarse también como sustantivo: es evidente que el definiens utilizado (una oración de relativo, equivalente, por tanto, de un adjetivo) nunca serviría para definir un sustantivo, lo que quiere decir que habría que dar una nueva definición, o, lo que es lo mismo, someter dicho definiens a un proceso de transformación sustantiva.

Una solución a este respecto muy utilizada por los diccionarios — aunque no la más conveniente- consiste en acudir a una definición indirecta, o más bien implicada, en un contexto referencial en que se indica el tipo de realidad a que el adjetivo se refiere. Se trata de las frecuentes pseudodefiniciones encabezadas por la fórmula, tan repetida a veces, «se dice»o «se aplica». Y así, siguiendo con el ejemplo anterior, tendríamos

adolescente. adj. Se dice de la persona que está en la adolescencia,

donde aparecen, aunque meramente implicados, el contorno y paráfrasis correspondientes.

Otra solución, sin duda más adecuada, consiste en la utilización de un contorno implicado en un contexto referencial de tipo genérico, formando parte de un enunciado distinto del de la definición, ahora en primera metalengua. El $D R A E$ en su última edi- 
ción ofrece una clara preferencia por este recurso — del que sin duda abusa a veces ${ }^{2}$ como se observa, por ejemplo, en

advenedizo. adj. Dicho de una persona: Que, siendo de origen humilde y habiendo reunido cierta fortuna, pretende figurar entre gentes de más alta condición social. U. t. c. s.

Más adecuada resulta, sin embargo, la solución adoptada por el Diccionario del español actual (DEA) de M. Seco y otros, al utilizar el contorno integrado, aunque convenientemente señalado haciéndolo figurar entre corchetes; así,

adúltero -ra $a d j$. [Pers.] que comete adulterio. $T b . n$.

Nada se dice, sin embargo, en este diccionario — como hasta el momento en ningún otro- acerca del carácter fluctuante del contorno [Pers(ona)], que, evidentemente, deja de ser contorno en la definición del sustantivo correspondiente. Lo mismo que el $D R A E$, este diccionario se limita a añadir que el definido puede usarse también como nombre, cosa que hace mediante la indicación $T b$. n., pero sin advertir, como digo, que el contorno pasa en este caso a formar parte del enunciado parafrástico, cosa que se podría haber conseguido fácilmente utilizando, por ejemplo, en vez de corchetes, otro tipo de paréntesis, que es lo que estamos haciendo por cierto en el Diccionario 'Coru$\tilde{n} a$ ' de la lengua española actual (DCLEA). ${ }^{3}$

\subsection{Con referencia a un complemento regido}

Las definiciones de los adjetivos, cuando estos se construyen con algún complemento régimen, como es el caso, entre otros, de apto, adicto, idóneo, digno, hábil, propenso, aficionado, adepto, seguidor, deben ofrecer información al respecto mediante el correspondiente contorno, el cual, por cierto, podría a primera vista interpretarse asimismo como un caso de contorno fluctuante si, al mismo tiempo, dicho complemento no es obligatorio, o lo que es lo mismo, siempre que el adjetivo definido pueda utilizarse de hecho sin él. Como ya dije antes, no se trata, sin embargo, propiamente de un contorno fluctuante, sino más bien opcional, ya que dicho contorno en ningún momento pasa a constituir un rasgo semántico intrínseco del adjetivo definido. Sea, por ejemplo, la siguiente definición, que tomo de M. Moliner:

aficionado, -a. («a») adj. y n. Se aplica al que tiene afición por cierta cosa,

donde he subrayado por cierta cosa porque representa el complemento régimen de aficionado - aunque con la diferencia de que la preposición por debe sustituirse por $a$, según se observa en el paréntesis inicial-y constituye, por tanto, el contorno definicional, contorno que aparece en el ejemplo, dado por la propia lexicógrafa aragonesa,

Los aficionados al deporte de la nieve.

\footnotetext{
${ }^{2}$ Véase a este respecto lo dicho en Porto (2009: 253).

${ }^{3}$ Cf. Porto y otros (2008: 33).
} 
Tengamos, no obstante, en cuenta que en el DUE no se hace ninguna observación respecto a que dicho complemento de régimen no es obligatorio, según se demuestra en el contexto:

El estadio estaba lleno de aficionados.

Ahora bien, ¿podemos, a partir de este hecho, concluir que el complemento régimen ha pasado a formar parte de los rasgos semánticos intrínsecos de la palabra aficionado? Es evidente que no. En realidad no nos hallamos ante un nuevo caso de contorno fluctuante, sino simplemente de un contorno opcional, es decir, que puede o no aparecer en la utilización discursiva o sintagmática del definido. Digamos que dicho contorno se refiere a un complemento de régimen, complemento que a veces no se expresa debido a su carácter indeterminado o fácilmente deducible del contexto, según ocurre, por ejemplo, en un enunciado como

En España el fútbol tiene más aficionados que el golf,

donde, evidentemente, se entiende «aficionados al fútbol»; pero el adjetivo no indica por sí mismo aquello por lo que se siente afición.

\section{EN LAS DEFINICIONES DE LOS VERBOS}

Es sobre todo en las definiciones de los verbos donde aparece con mayor frecuencia el contorno fluctuante, contorno que puede referirse tanto al sujeto como a cualquier complemento verbal, siendo especialmente destacable por su relativa frecuencia el correspondiente al objeto directo o implemento. Para ver un ejemplo de cada una de estas posibilidades, considérense las siguientes definiciones tomadas del $D R A E$ :

llover. intr. impers. Caer agua de las nubes.

martillar. tr. Batir y dar golpes [a algo] con el martillo.

conducir. tr. Esp. Guiar un vehículo automóvil,

donde los elementos subrayados constituyen casos de contorno fluctuante, dependiendo, en el primer caso, de que el verbo definido sea o no impersonal:

Ayer llovió (= cayó agua de la nubes) todo el día

Ayer llovió (= cayó de las nubes) agua menuda todo el día.

En el segundo ejemplo, el sintagma preposicional —en este caso un complemento instrumental — puede o no aparecer contextualmente con el definido; así,

Es muy molesto el ruido que producen al martillar (= dar golpes con el martillo) la roca.

Es muy molesto el ruido que producen al martillar (= dar golpes) con el martillo mecánico la roca. 
Y, finalmente, en el tercer caso el elemento subrayado constituirá o no contorno según que el verbo sea transitivo o intransitivo, como se demuestra en los contextos siguientes:

Feliciano no conduce (= guía vehículos automóviles).

Feliciano conduce (= guía) un Ford Fiesta.

\subsection{Con referencia al sujeto.}

Como acabamos de ver, cuando el contorno fluctuante corresponde al sujeto, su ausencia o presencia va ligada al hecho de que el verbo funcione o no como impersonal y, por lo tanto, en este último caso, con sujeto interno, como ocurre con los verbos meteorológicos del tipo llover, nevar, granizar, tronar, rociar, relampaguear. Todos estos verbos, en efecto, podemos decir que llevan incluido en su semema el sujeto, que es, respectivamente, agua o lluvia (o agua lluvia), nieve, granizo, trueno(s), rocío y relámpago $(s)$, los cuales solo se hacen expresos contextualmente o bien cuando dichos sujetos necesitan alguna precisión o determinación, o bien asimismo - en algunos casos - cuando, por un proceso de extensión metafórica, desempeñan esa función palabras que representan objetos que guardan cierta similitud con la lluvia, la nieve, el granizo, etc. ${ }^{4}$ Esto último por cierto, en algunos diccionarios, da lugar a acepciones independientes; de ahí que, por ejemplo, para granizar, el $D R A E$ registre las dos acepciones siguientes, una impersonal (con sujeto interno) frente a otra de carácter totalmente personal:

granizar. intr. impers. Caer granizo.|| 2. intr. Caer con ímpetu y menudeando como el granizo. ${ }^{5}$ U. t. c. tr.

Es precisamente este fenómeno de extensión metafórica lo que hace posible la aceptabilidad de expresiones como, por ejemplo,

En la batalla tronaban continuamente los cañones

Empezó a llover gran cantidad de piedras y de arena.

No hace falta decir que ningún diccionario, con el de la Academia al frente, señalan para nada la condición alternativa del contorno o elemento interno representado por los elementos lluvia, granizo, trueno, etc., si exceptuamos el caso del $D E A$ y, solo hasta cierto punto, del $D U E$. Este último, efectivamente, se limita a señalar en algunos casos el carácter interno del sujeto cuando el verbo es terciopersonal, mientras que el $D E A$ establece en realidad dos acepciones - impersonal y personal - aunque con la misma definición, colocando — es cierto — en la personal dicho sujeto entre corchetes, es de-

\footnotetext{
${ }^{4}$ A propósito de la definición lexicográfica de estos verbos, véase Calzado Roldán (2008).

${ }^{5}$ Notemos que en este última definición el contorno no aparece expreso, teniendo por tanto carácter implícito, noción que no hay que confundir con la de contorno opcional: el primero, pese a representar un argumento del verbo, no se indica en el definiens por sobreentenderse fácilmente, mientras que el segundo — como ya hemos visto - es el contorno cuya utilización con el definiendum no es obligatoria.
} 
cir, como contorno, solución que, a mi modo de ver, resulta poco económica. Mucho más rentable sin duda sería, como hacemos en el DCLEA, colocar ese sujeto entre paréntesis redondos en vez de corches para indicar precisamente que se trata de un elemento interno del verbo, pero que puede aparecer en superficie en algunos contextos, justamente en los de carácter personal. Por todo ello propondría, por mi parte, definiciones como

llover. intr. Caer (agua lluvia) de las nubes

granizar. intr. Caer de las nubes (granizo),

etc. En realidad se trata de una sola acepción, susceptible, claro, de dos construcciones diferentes, sin y con sujeto externo.

Claro que en estos casos los elementos lluvia, granizo, trueno, etc. podría pensarse que no son contornos en el sentido más estricto de la palabra, toda vez que repiten la raíz del definiendum y, por lo tanto, se trata más bien de lo que viene llamándose «complementos internos» del verbo. Dado, no obstante, que su comportamiento no varía del de un contorno fluctuante y que, además, pueden, por extensión, ser materializados, en otros contextos, por palabras que ya no tienen nada que ver con esa raíz (en llueven piedras, por ejemplo), no vemos ningún inconveniente en tratarlos como verdaderos contornos de ese tipo.

En cambio, no constituye un caso de contorno fluctuante el sujeto que aparece en la definición de multitud de verbos que, además de la normal construcción personal, son susceptibles de emplearse también impersonalmente. Sea, en efecto, entre las muchas que podríamos citar, la siguiente definición tomada del $D E A$ :

robar tr Tomar [alguien] para sí [algo ajeno] sin consentimiento del dueño, y esp. mediante violencia o engaño,

según la cual el sujeto del definido será alguien, esto es, un sustantivo que incluya el rasgo semántico 'persona o humano'; de ahí la posibilidad de expresiones como

Feliciano robó la herencia de sus hermanos.

Alguien me robó la cartera en el metro.

Dada, sin embargo, la posibilidad de que dicho verbo puede formar parte de oraciones impersonales del tipo

Me robaron la cartera en el metro,

podría arrastrar fácilmente a pensar que el contorno [alguien] de la definición es fluctuante, conclusión evidentemente falsa, ya que no se trataría de un sujeto interno, sino simplemente indeterminado, por lo que habría que hablar en todo caso de un contorno meramente opcional. Ya sé que con esto no descubro ningún Mediterráneo, pues son muchos los gramáticos que han señalado una gran diferencia entre las llamadas «im- 
personales naturales» (llueve, graniza), cuya impersonalidad es semántica, y las «impersonales de sujeto indeterminado», con impersonalidad meramente sintáctica. ${ }^{6}$

\subsection{Con referencia a un complemento preposicional}

Así pues, fuera de los verbos meteorológicos, no se detecta en español ningún otro caso de contorno fluctuante concerniente al sujeto. No ocurre lo mismo, sin embargo, cuando el contorno corresponde a una función complementaria con o sin preposición, esto es, de suplemento o complemento adverbial y, sobre todo - como expondré en el próximo apartado (2.3.) — de implemento u objeto directo.

Entre los muchos casos de complemento preposicional, cabe señalar ante todo y en primer lugar aquellos en que ese complemento corresponde - lo mismo que acabamos de ver a propósito de la función sujeto - a una característica interna del definiendum, cosa que ocurre, por ejemplo, en las definiciones de verbos como embotellar, aporrear, adornar, enterrar, atronar, alinear, atenazar, que, según el $D R A E$, serían las siguientes:

embotellar. tr. Meter el vino u otro líquido o producto en botellas.

aporrear. tr. Dar golpes insistentemente, con una porra o con cualquier otra cosa.

adornar. tr. Engalanar con adornos.

enterrar. tr. Poner debajo de tierra.

atronar. tr. Asordar o perturbar con ruido como de trueno.

alinear. tr. Colocar tres o más personas o cosas en línea recta.

atenazar. tr. Sujetar fuertemente con tenazas o como con tenazas.

El carácter interno de los sustantivos que actúan como términos de la preposición es claro porque su correspondiente lexema coincide con el del verbo definido, siendo este una especie de derivado — quizá más correctamente, un desarrollo- del sustantivo respectivo. Es obvio, por tanto, que los elementos subrayados en las anteriores definiciones no constituirían en principio contornos definicionales, pero pueden convertirse en tales al aparecer - como ocurría con el sujeto interno - al lado del verbo en ciertos contextos, como, por ejemplo, respectivamente,

Hemos embotellado toda la cosecha de vino en botellas de litro y medio.

Estuvo aporreando la puerta con el palo que llevaba en la mano.

Adornaron la ciudad con bombillas de colores.

Quedó enterrado debajo de aquella tierra humedecida por la incesante lluvia.

La comparsa atronaba el pueblo con aquellos tambores y cencerros.

\footnotetext{
${ }^{6}$ Véase a este propósito, por ejemplo, Fernández Soriano y Táboas Baylín (1999: 1725 y ss.).
} 
Para entrar en el colegio, los niños se alinearon en una fila interminable.

Le atenazaba con sus brazos.

Hay que hablar, pues, en estos casos de verdaderos complementos internos constitutivos, por ello, de contornos también fluctuantes. Por lo demás, la aparición explícita de estos elementos en el discurso, se produce, como en el caso del sujeto interno, cuando van acompañados de alguna determinación o, por otra parte, el sustantivo en cuestión es sustituido por otro, generalmente un hipónimo o, por extensión metafórica, una palabra indicadora de una realidad semejante a la expresada por aquel. También, naturalmente, habrán de incluirse en este caso los sinónimos.

Más problemático sin duda se presenta el caso en que el complemento preposicional, presente en una definición, no está lexemáticamente emparentado con el verbo y, por lo tanto, en tal circunstancia más que de un complemento interno cabe hablar de un complemento de régimen del verbo, esto es, un suplemento o complemento adverbial. ${ }^{7}$ Me refiero, naturalmente, a cuando la presencia de ese complemento no es de hecho absolutamente obligatoria en todos los contextos a que da lugar el definiendum. Es lo que ocurre, por ejemplo, con definiciones como las siguientes:

aterir. tr. defect. Pasmar de frío. U. m. c. prnl.

chocar. intr. Dicho de dos cosas: Encontrarse violentamente una con otra, como una bala contra la muralla, un buque con otro, etc.

confiar. tr. Depositar en alguien, sin más seguridad que la buena fe y la opinión que de él se tiene, la hacienda, el secreto o cualquier otra cosa.

casar. intr. Contraer matrimonio. U. m. c. prnl.

Naturalmente, en este último caso existe un contorno implícito, con alguien, que es sin duda un complemento exigido por casar, con independencia de que este pueda de hecho aparecer sin él:

Amalita se casó ayer con Rafael / Amalita se casó ayer.

Pese a que el contorno hace referencia en estos casos a un verdadero actante o argumento del verbo definido, no está claro que se trate de un contorno fluctuante en todos ellos: mi conclusión es que unas veces puede serlo y otras, en cambio, no. Examinemos cada una de las definiciones en concreto:

a) Desde luego el complemento de frío parece funcionar como un verdadero contorno fluctuante, si tenemos en cuenta la total equivalencia semántica entre las expresiones:

Estaba aterido de frío = Estaba aterido,

lo que, a mi juicio, quiere decir que aterido en la segunda frase posee el significado de 'pasmado de frío', es decir, incluye semánticamente el complemento.

\footnotetext{
${ }^{7}$ Véase a este respecto Alarcos (1968, 1986 y 1990), Bosque (1983), Martínez (1986), Porto (1987), Rodríguez Díez (1987) y Rojo (1985 y 1990).
} 
b) Ahora bien, este mismo razonamiento podría pensarse que sirve para los casos de chocar, confiar y casar, puesto que, cuando decimos que Amalita se casó ayer, ya se sabe que tuvo que casarse con alguien, y en expresiones como

\section{El autobús chocó.}

\section{Debes confiar más}

es verdad de Perogrullo que el autobús tuvo que chocar con algo, y que la confianza se ha de depositar en algo o alguien. Notemos, sin embargo, que tanto con algo como en alguien no constituyen en sí ninguna nota léxico-semántica, sino meros comodines, indicadores de una función sintáctica, que en todo caso habrá que rellenar con verdaderas unidades léxicas, como se hace, por ejemplo, en

El autobús chocó con un camión.

Debes confiar más en tu marido,

unidades léxicas que, evidentemente, no están contenidas en los respectivos verbos. Nos hallamos, en definitiva, en este caso ante contornos opcionales, que pueden desaparecer del contexto cuando son indeterminados o inespecíficos, situación que, como se ve, no es diferente de la del sujeto indeterminado que veíamos más arriba.

Evidentemente, no hay que confundir este último caso con el de complementos como los que aparecen en este otro tipo de contextos:

Me he enterado de la noticia por el periódico.

Lo condenaron por malos tratos a su esposa.

Rafael estudia Caminos en la Universidad Politécnica

Viajó en bicicleta por toda Europa.

La razón es bien sencilla: porque dichos complementos, que, como en el caso anterior, son opcionales, no constituyen - frente a ellos - ningún complemento de régimen, es decir, no tienen carácter argumental y, por lo tanto, no funcionan como verdaderos actantes de los verbos enterarse, condenar, estudiar y viajar. Por ese motivo, lógicamente, no constituyen ningún contorno $\mathrm{y}$, por tanto, no deberían formar parte de las correspondientes definiciones, cosa que se cumple, por ejemplo, en el DRAE tan solo en los dos primeros casos, a saber:

enterar. tr. Informar a alguien de algo o instruirlo en cualquier negocio. U. t. c. prnl.

condenar. tr. Dicho de un juez: Pronunciar sentencia, imponiendo al reo la pena correspondiente o dictando en juicio civil, o en otras jurisdicciones, fallo que no se limite a absolver de la demanda.

No ocurre, sin embargo, lo mismo con estudiar y viajar, en cuyas definiciones

estudiar. tr. Cursar en las universidades o en otros centros docentes. U. t. c. intr.

viajar. intr. Trasladarse de un lugar a otro, generalmente distante, por cualquier me$\underline{\text { dio de locomoción }}$ 
es evidente que sobran los elementos subrayados porque ni el verbo estudiar ni el verbo viajar los exigen propiamente. Y no los exigen no solo, naturalmente, porque se trata de complementos circunstanciales normales - uno es locativo y el otro indica el medio - de carácter opcional, ${ }^{8}$ sino además porque tales elementos no sirven para oponer o diferenciar semánticamente cada uno de esos verbos de ningún otro de su correspondiente paradigma.

No podemos, sin embargo, decir lo mismo del complemento preposicional que aparece, por ejemplo, en la siguiente definición tomada del $D E A$ :

freír. tr. Guisar o preparar [un alimento] teniéndolo el tiempo preciso [en aceite o grasa hirviendo],

donde en aceite o grasa hirviendo es presentado como contorno; pero es un contorno fluctuante sencillamente porque existe una solidaridad entre dicho complemento y freír - solidaridad por la que se opone a cocer y asar - y, por lo tanto, puede de alguna manera considerarse incluido en el propio contenido del verbo cuando dicho complemento no se halla explícito en el discurso; por ejemplo, en

Me falta freir las patatas.

En definitiva, pues, se puede hablar también de contorno fluctuante cuando entre el complemento preposicional de la definición y el verbo definido existe una relación de solidaridad. Esto mismo ocurre, como veremos más abajo, cuando la solidaridad se establece con el objeto directo.

\subsection{Con referencia al implemento u objeto directo}

He dejado para el final la consideración del contorno fluctuante con referencia al objeto directo o implemento porque, además de ser el caso más frecuente, es también el que mayores problemas plantea a la descripción lexicográfica. Para empezar, este tipo de contorno se da en verbos transitivos susceptibles de perder, en determinados contextos, su objeto directo, o, por el contrario, en verbos intransitivos que, también en determinadas circunstancias, se transitivizan permitiendo el desarrollo de un implemento $\mathrm{u}$ objeto directo, aunque en algunos casos suponga la repetición de la raíz del definiendum, como es el conocido caso de

Juan vive una vida feliz,

en el que precisamente por eso se habla de «complemento o acusativo interno». Los diccionarios en estos casos suelen ser muy poco precisos, pues, aunque a veces, sepa-

${ }^{8}$ Otra cosa, naturalmente, es que fuesen obligatorios, pues, en ese caso, se trataría de lo que Rojo llama «complemento adverbial». Por eso en la definición «residir. intr. Estar establecido en un lugar,», en algún lugar, pese a ser un locativo, representa un verdadero complemento argumental, dado su carácter obligatorio. Como bien dice el profesor compostelano, no sería posible decir «*Residen», frente a «Residen en Vigo».

9 Ambos se definirían lo mismo que freír con la diferencia de que dicho complemento se sustituiría por en agua hirviendo y directamente al fuego, respectivamente. 
ran las dos posibilidades - transitiva e intransitiva o absoluta - en acepciones diferentes, para cada una de las cuales se establece una definición diferente acorde con esas características (observemos a este respecto las siguientes definiciones de M. Moliner a propósito de bizcar:

bizcar. 1 intr. Bizquear: mirar bizco. 2 tr. Torcer los 'ojos al mirar: 'Bizca un ojo'), en la mayor parte de los casos se contentan con ofrecer una sola definición señalando, sin más explicación, que el verbo puede usarse también como intransitivo o absoluto, si se define como transitivo, o, por el contrario, que puede usarse también como transitivo, si la definición corresponde a la visión intransitiva. No se explica, por otro lado, el cambio que con el paso de transitivo a intransitivo y viceversa puede experimentar un actante, como puede verse, por ejemplo, entre otras muchas, en la siguiente definición:

vivir. intr. Tener vida. U. t. c. tr.

donde no se aclara que vida, que funciona como rasgo interno en la definición intransitiva, pasa a ser contorno - contorno fluctuante, por tanto - en la transitiva.

Pero la cosa se complica todavía más, si tenemos en cuenta que este no es el único tipo de modificación que se produce en el paso de un verbo intransitivo a transitivo $\mathrm{y}$, sobre todo, de transitivo a intransitivo. Veamos si no esta otra definición del $D R A E$ con igual estructura que la anterior:

concluir. tr. Acabar o finalizar algo. U. t. c. intr.

donde no se advierte que el contorno - que por cierto aquí no es fluctuante — representado por el objeto directo del definiens pasa en la construcción intransitiva a sujeto. No hay que olvidar, por otro lado, que el contorno definicional representante del objeto directo del definido no siempre es, como observaré luego, de carácter homogéneo (esto es, desempeña esa misma función sintáctica en el definiens), como ocurre en los casos anteriores, sino que con frecuencia puede ofrecer carácter heterogéneo.

Lo que, desde luego, resulta absolutamente patente es que, en general, en los diccionarios - y lo mismo en las gramáticas al uso - no parece subyacer una idea clara acerca de las relaciones o correspondencias que se producen o pueden producirse entre un verbo en construcción transitiva y en la intransitiva o absoluta (o, también, entre una transitiva triactancial o de tres lugares y otra biactancial o de dos). Precisamente la primera dificultad con que nos encontramos es la distinción entre los caracteres intransitivo y absoluto, que para algunos parece que serían una misma cosa; por ejemplo, en el $D U E$ de M. Moliner todo verbo que, en una misma acepción, se puede construir con y sin objeto directo es marcado con la indicación «tr. o abs.», y no así cuando se considera que en ambos usos pertenecen a acepciones distintas - o una es subacepción de otra-, ${ }^{10}$ como, por ejemplo, en

${ }^{10}$ Hay que exceptuar el caso en que la función de implemento alterna con la de suplemento o complemento de régimen preposicional, situación en que se da una sola definición y se marca como $t r$. o intr. Tal es el caso de abjurar, que veremos más adelante. 
musitar. intr. Hablar sin emitir voz. 1 Bisbisear, mistar, hablar en voz baja. 5 tr. Decir en esa forma alguna 'cosa: 'Musitó una oración',

que, obviamente, constituyen el mismo significado. La Academia, por su parte, nunca utiliza la calificación de absoluto, aplicando siempre la caracterización de intransitivo.

Realmente, como es bien sabido, aunque, en una visión meramente superficial, una construcción absoluta no se diferencia de una intransitiva - ambas se caracterizan por no llevar complemento directo-, no cabe duda de que responden a estructuras sintácticas distintas, aunque luego en la práctica — todo hay que decirlo - no siempre resulte fácil distinguirlas: la primera sigue siendo transitiva, pues se considera que sigue teniendo objeto directo, aunque no explícito, dado su carácter inespecífico o fácilmente deducible de la situación o contexto (pensemos, por ejemplo, en

Estuve una hora esperando en la estación,

donde, obviamente, se esperó a alguien o algo — por ejemplo, el tren- que no está incluido en el significado de esperar), mientras que, en el segundo, dicho objeto resulta relativamente específico y de alguna manera pasa a formar parte del significado del verbo; así en

\section{Esta tarde tengo que segar;}

el verbo segar está intransitivizado porque, pese a que hierba, césped o mies son elementos exigidos por él como implementos en virtud de una solidaridad, pasan en este contexto a formar parte de su significado como semas determinantes, mediante los cuales este verbo se opone, por ejemplo, a cortar, talar, desmochar, etc. ${ }^{11}$ Así pues, en el primer caso, el verbo sigue siendo claramente transitivo, cosa que no se puede decir del segundo. Y, naturalmente, no hace falta observar que solo cuando el verbo se intransitiviza realmente al perder el objeto directo cabe hablar, en la correspondiente definición, de contorno fluctuante, que subrayamos en la siguiente definición del $D R A E$ :

segar. tr. Cortar mieses o hierba con la hoz, la guadaña o cualquier máquina a propósito.

Pero en realidad todo esto hay que encuadrarlo dentro de todo un conjunto de posibilidades transformativas que explican el paso de un verbo transitivo a intransitivo o viceversa y, por consiguiente, las relaciones semántico-sintácticas existentes entre ambas construcciones. Veamos cuáles son esas posibilidades:

a) Como acabamos de ver, la primera posibilidad consistirá en que el objeto directo del verbo definido - objeto que constituye el contorno en la correspondiente definición- pase a ser indicado por el propio verbo, convirtiéndose, por consiguiente, en parte de la paráfrasis definicional. Es lo que ocurre en el ejemplo anterior y también en estos otros:

\footnotetext{
${ }^{11}$ Véase Coseriu (1977: 151-152).
} 
rondar. intr. Andar de noche paseando las calles. U. t. c. tr.

respirar. intr. Dicho de un ser vivo: Absorber el aire, por pulmones, branquias, tráquea, etc., tomando parte de las sustancias que lo componen, y expelerlo modificado. U. t. c. tr.

susurrar. intr. Hablar quedo, produciendo un murmullo. U. t. c. tr.

torear. intr. Lidiar los toros en una plaza. U. t. c. tr.

amusgar. tr. Dicho de un caballo, de un toro, etc.: Echar hacia atrás las orejas en ademán de querer morder, tirar coces o embestir. U. t. c. intr.

En todos los casos, pues, hay que hablar de contorno fluctuante.

b) Otra posibilidad viene dada por el caso en que el verbo en su uso intransitivo pasa a integrar la clase de los llamados inacusativos: el sujeto se corresponde con el objeto directo del correspondiente transitivo. Ya hemos visto antes el caso de concluir, pero existen muchos otros, hasta el punto que se puede decir que es este el tipo de relación más frecuente en los verbos que admiten las dos posibilidades, sobre todo si incluimos en el uso transitivo la construcción pronominal. Veamos otros ejemplos:

enfermar. intr. Ponerse alguien enfermo. 2. tr. Poner a alguien enfermo.

abrir. tr. Separar del marco la hoja o las hojas de una puerta o ventana, haciéndolas girar sobre sus goznes, o quitar o separar cualquier otra cosa con que esté cerrada una abertura, para que deje de estarlo. U. t. c. intr. y c. prnl. Esta puerta abre bien o abre mal. Abrirse una puerta.

aumentar. tr. Dar mayor extensión, número o materia a algo. U. t. c. intr. y c. prnl.

cicatrizar. tr. Completar la curación de las llagas o heridas, hasta que queden bien cerradas. U. t. c. intr. y c. prnl.

disminuir. tr. Hacer menor la extensión, la intensidad o el número de algo. U. t. c. intr. y c. prnl.

donde, como fácilmente puede comprobarse, lo subrayado, que actúa como objeto directo en la construcción transitiva del definido, pasa a sujeto en la correspondiente construcción intransitiva o pronominal. Como en ninguna de las dos construcciones el elemento en cuestión deja de ser un argumento o actante del verbo, no constituye, lógicamente, nunca un contorno fluctuante.

c) Por último, una tercera posibilidad consiste en que el complemento directo del verbo en uso transitivo sea complemento preposicional en el correspondiente intransitivo, circunstancia en la que, por tanto, tampoco se da un contorno fluctuante. Considérese esta definición de M. Moliner:

abjurar. tr. e intr. Abandonar solemne o públicamente una 'creencia, particularmente religiosa: 'Abjurar el [o del] catolicismo',

donde creencia, que aparece marcada como contorno complemento directo, puede pasar, según el ejemplo aducido, a complemento con $d e$. 
Esto supuesto, el contorno fluctuante referido al objeto directo solo caracteriza las definiciones de aquellos verbos que, en una misma acepción, son susceptibles de emplearse como transitivos e intransitivos (o transitivos trivalentes y bivalentes) y, además, dicho objeto directo constituye un verdadero rasgo semántico interno del verbo en su uso intransitivo (o transitivo de dos lugares). Este hecho, por lo demás, se produce o bien cuando el verbo, primariamente intransitivo (o transitivo bivalente), es susceptible de generar sintagmáticamente un «acusativo interno» o, lo que es lo mismo, un implemento que de algún modo repite el lexema o base léxica del verbo, o bien cuando se trata de un verbo, primariamente transitivo, que selecciona o exige por solidaridad ese implemento u objeto directo. Esto último es particularmente claro en los casos en que el verbo se opone a otro $u$ otros de su paradigma precisamente por ese rasgo, en principio meramente contextual, como hemos visto que ocurría con el verbo segar; pero también, por ejemplo, con afeitar:

afeitar. tr. Raer con navaja, cuchilla o máquina la barba o el bigote, y, por ext., el pelo de cualquier parte del cuerpo.

Existe aquí una clara solidaridad entre afeitar y pelo, pues, gracias a ella, este verbo se opone a cortar, segar, talar, etc. La parte subrayada constituye, por otro lado, un verdadero contorno fluctuante porque este verbo, que es transitivo de tres lugares o actantes, puede construirse sin ese complemento - pero incluyéndolo en su propio significado- - pasando a objeto directo el indirecto, esto es, convirtiéndose el verbo en transitivo de dos lugares. Así,

Yo me afeito la barba todos los días $\rightarrow$ Yo me afeito todos los días,

donde me afeito equivale, respectivamente, a 'me corto al ras' y 'me corto al ras la barba'. ${ }^{12}$ Notemos, por cierto, que muy distinto sería el caso de afeitar en este otro contexto, sin objeto directo:

Es un peluquero que afeita muy bien,

donde sin duda el verbo sigue siendo transitivo aunque en construcción absoluta: ya se sabe que «afeita a alguien», pero este hecho pertenece a nuestro conocimiento y experiencia del mundo, no a la lengua.

Como ya queda señalado a propósito del sujeto y del complemento de régimen cuando dan lugar a contornos fluctuantes, también en el caso del objeto directo surgido como «acusativo interno» o, como en el último ejemplo, por solidaridad, lo que realmente representa en superficie a ese contorno es una concreción o especificación suya, mediante otra palabra o por la misma de la definición con algún complemento. De ahí que en el ejemplo anterior el contorno fluctuante, representado genéricamente, por pelo, pueda aparecer en superficie como barba, bigote, pelo de la cabeza, etc.; y lo mismo ocurre, en el caso de comer, con comida o alimento, los cuales pueden ser susti-

${ }^{12}$ La definición del $D R A E$ nada informa acerca de este particular. Por eso, quizás, sea preferible, por incluir los dos actantes complementos, la del DUE: «afeitar. Quitar a ’alguien, cortándolo a ras de la piel, el pelo de la barba o bigote o de cualquier otro sitio del cuerpo». De todos modos, esta definición correspondería tan solo a la segunda posibilidad, esto es, como verbo bivalente. 
tuidos por palabras semánticamente más precisas como paella, chuleta, tarta de manzana, etc. En el caso de las solidaridades, todo esto tiene que ver, obviamente, con el hecho de que el contorno ponga de manifiesto una afinidad, una selección o una implicación, es decir, de que el lexema determinante que representa sea un clasema, un archilexema o un lexema. ${ }^{13}$ Así, por ejemplo, continuando con los verbos que significan 'cortar', en la definición

trasquilar. tr. Cortar el pelo o la lana a algunos animales,

el contorno representa una afinidad - es decir, el complemento directo ha de incluir el clasema 'animal' - , mientras que en

talar. tr. Cortar por el pie una masa de árboles

responde más bien a una selección, lo que quiere decir que el contorno correspondiente puede estar representado en el discurso mediante cualquier elemento perteneciente al campo o paradigma semántico correspondiente. Tanto en un caso como en otro, por tanto, son posibles mayores concreciones en la realización de la lengua:

Ayer trasquilamos las ovejas

Talaron todo un robledal.

La implicación, que, lógicamente, se da pocas veces en la práctica, no admitiría especificación léxica, pero sí sintáctica; así, de

guiñar. tr. Cerrar un ojo momentáneamente quedando el otro abierto, a veces con disimulo por vía de señal o advertencia,

se pueden construir expresiones como, por ejemplo,

Nos guiñó el ojo derecho.

Y ya para terminar, tan solo me resta añadir a todo lo dicho sobre el contorno fluctuante indicador del objeto directo del verbo definido que dicho contorno — según ya queda sugerido - no siempre ofrece carácter homogéneo, como ocurre en la inmensa mayoría de los ejemplos que hemos venido viendo. Quiero decir que no siempre desempeña en el definiens la misma función sintáctica de implemento, aunque, naturalmente, esto sea lo ideal en la definición de los verbos transitivos. Hay casos, efectivamente, en que el contorno es heterogéneo, como lo prueban los siguientes ejemplos:

embestir. tr. Ir con ímpetu sobre alguien o sobre algo. El toro embistió al torero

navegar. intr. Ir un vehículo, o ir en un vehículo, por el agua. U. t. c. tr.

ejercer. tr. Practicar los actos propios de un oficio, facultad o profesión. U. t. c. intr. Es abogado, pero no ejerce.

arbitrar. intr. Dep. Ejercer de árbitro en un partido. U. t. c. tr.

\footnotetext{
${ }^{13}$ Véase Coseriu (1977: 153-155).
} 
donde, como se ve, los elementos subrayados, que habrán de actuar como objetos directos del definiendum, son, sin embargo, complementos preposicionales en el definiens.

\section{REFERENCIAS BIBLIOGRÁFICAS}

AlARCOS LlORACH, E. (1966): «Verbo transitivo, verbo intransitivo y estructura del predicado», AO, XVIII, pp. 5-17 (también en sus Estudios de gramática funcional del español, Madrid, Gredos, 1987, pp. 148 y ss.).

(1986): «Prólogo» a H. Martínez, El suplemento en español, Madrid, Gredos, pp. $3-5$.

(1990): «La noción de suplemento», en Prof. F. Marsá: Jornadas de Filología, Barcelona, Universitat de Barcelona, pp. 209-221.

BosQUE, I. (1983): «Dos notas sobre el concepto 'suplemento' en la gramática funcional», Dicenda, 2, pp. 147-156.

Calzado Roldán, A. (2008): «La definición lexicográfica de los verbos impersonales de fenómenos naturales», en http://descargas.cervantesvirtual.com/servlet/SirveObras/679 273998701472322679/031336.pdf?incr=1 [fecha de consulta: 25-VIII-2010].

FERnÁNDEZ SORIANO, O. y S. TÁBOAS BAYLÍN (1999): «Construcciones impersonales no reflejas», en I. Bosque y V. Demonte, dirs., Gramática descriptiva de la lengua española, Madrid, Real Academia-Espasa Calpe, pp. 1723-1744.

MARTíNEZ GARCÍA, H. (1986): El suplemento en español, Madrid, Gredos.

Porto Dapena, J. A. (1987): «Sobre el suplemento. Notas al hilo de una publicación reciente», Thesaurus, XLII, pp. 122-133.

(1997): «Algunas observaciones sobre el contorno de la definición lexicográfica», en y M. Almeida y J. Dorta, eds., Contribuciones al estudio de la lingüística hispánica. Homenaje al profesor R. Trujillo, Tenerife, Montesinos, II, pp. 211-226.

(2009): Lexicografia y metalexicografia: estudios, propuestas y comentarios, anexo 12 de la Revista de Lexicografía, A Coruña, Universidade da Coruña.

E. Conde Noguerol, F. Córdoba Rodríguez y M. Muriano Rodríguez (2008): El Diccionario 'Coruña' de la lengua española actual: planta y muestra, anexo 9 de la Revista de Lexicografia, A Coruña, Universidade da Coruña. 
Rodríguez DÍEZ, B. (1987-1988) «Sintagmas preposicionales concordados», AO, XXXVII, pp. 271-293.

RoJO, G. (1985): «En torno a los complementos circunstanciales», en Lecciones del I y II cursos de lingüística funcional, Oviedo, Universidad de Oviedo, pp. 181-191.

(1990): «Sobre los complementos adverbiales», en Prof. F. Marsá: Jornadas de Filología, Barcelona, Universitat de Barcelona, pp. 153-171. 